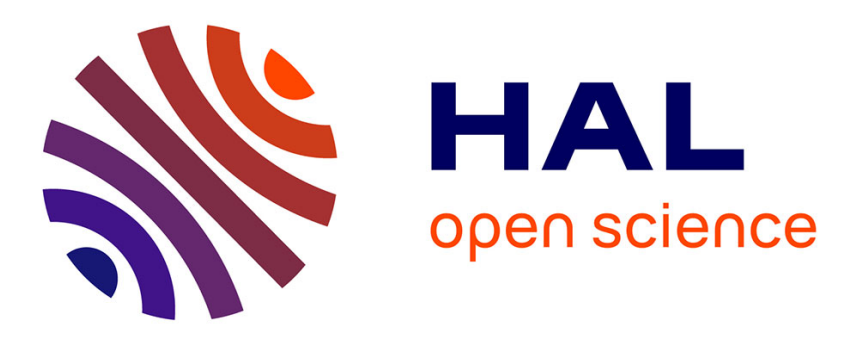

\title{
TransPoly: A theoretical model to quantify the dynamics of water transfer through nanostructured polymer films
}

Giana Almeida Perré, Sandra Domenek, Patrick Perre

\section{To cite this version:}

Giana Almeida Perré, Sandra Domenek, Patrick Perre. TransPoly: A theoretical model to quantify the dynamics of water transfer through nanostructured polymer films. Polymer, 2020, 191, pp.122256. 10.1016/j.polymer.2020.122256 . hal-03140177

\author{
HAL Id: hal-03140177 \\ https://hal.science/hal-03140177
}

Submitted on 4 Nov 2021

HAL is a multi-disciplinary open access archive for the deposit and dissemination of scientific research documents, whether they are published or not. The documents may come from teaching and research institutions in France or abroad, or from public or private research centers.
L'archive ouverte pluridisciplinaire HAL, est destinée au dépôt et à la diffusion de documents scientifiques de niveau recherche, publiés ou non, émanant des établissements d'enseignement et de recherche français ou étrangers, des laboratoires publics ou privés. 


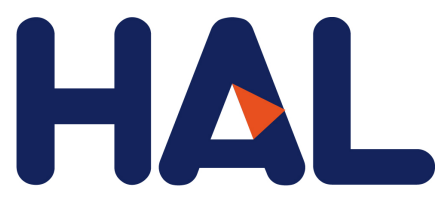

archives-ouvertes

\section{TransPoly: A theoretical model to quantify the dynamics of water transfer through nanostructured polymer films}

Giana Almeida Perré, Sandra Domenek, Patrick Perre

\section{To cite this version:}

Giana Almeida Perré, Sandra Domenek, Patrick Perre. TransPoly: A theoretical model to quantify the dynamics of water transfer through nanostructured polymer films. Polymer, Elsevier, 2020, 191, pp.122256. 10.1016/j.polymer.2020.122256 . hal-03140177

\section{HAL Id: hal-03140177 \\ https://hal.archives-ouvertes.fr/hal-03140177}

Submitted on 4 Nov 2021

HAL is a multi-disciplinary open access archive for the deposit and dissemination of scientific research documents, whether they are published or not. The documents may come from teaching and research institutions in France or abroad, or from public or private research centers.
L'archive ouverte pluridisciplinaire HAL, est destinée au dépôt et à la diffusion de documents scientifiques de niveau recherche, publiés ou non, émanant des établissements d'enseignement et de recherche français ou étrangers, des laboratoires publics ou privés. 


\title{
TransPoly: A theoretical model to quantify the dynamics of water transfer through nanostructured polymer films
}

\author{
Giana Almeida ${ }^{a, *}$, Sandra Domenek ${ }^{a}$, Patrick Perré ${ }^{b, c}$ \\ a Université Paris-Saclay, INRAE, AgroParisTech, UMR SayFood, 91300, Massy, France \\ ${ }^{\mathrm{b}}$ Université Paris-Saclay, CentraleSupélec, Laboratoire de Génie des Procédés et Matériaux, 91190, Gif-sur-Yvette, France \\ ${ }^{\mathrm{c}}$ CentraleSupélec, LGPM, Centre Européen de Biotechnologie et de Bioéconomie (CEBB), 3 rue des Rouges Terres, F-51110 Pomacle, France
}

\section{A R T I C L E I N F O}

\section{Keywords:}

Barrier properties

Chemical potential

Cellulose nanocrystals

Non-Fickian diffusion

Mathematical model

Relaxation time

\begin{abstract}
A B S T R A C T
Mass transfer of penetrants is among the most important physical properties of polymer films to properly ensure function during service. In the case of interaction between penetrants and polymer, non-Fickian diffusion can be observed. This phenomenon is described by numerous reports and a few models have been proposed. Nevertheless, few of them quantify Fickian and non-Fickian behaviour using parameters with clear physical meaning. The present work develops a new non-Fickian mass transport model: TransPoly (Transfer through Polymers). Based on coupled heat and mass transfer, it accounts for simultaneous Fickian transport and molecular relaxation. This model is applied to data of water vapour mass transfer in nanocomposites of polylactide and cellulose nanocrystals. The contribution of the non-Fickian mass transfer on water vapour sorption is highlighted. TransPoly can be applied to several kinds of polymers and used for prediction purposes once the parameters are determined on a learning database.
\end{abstract}

\section{Introduction}

The mass transfer properties in polymers are among of the most important physical properties for the use of these materials. When studying mass transfer into materials, the determination of diffusion coefficient is compulsory. This coefficient is the phenomenological parameter of the Fick's law (named after Adolf Fick, 1855), the basic law for mass migration into materials. In the absence of strong coupling effect and with Dirichlet conditions, the solution of the Fick's law exhibits a linear mass uptake of the diffusing material, followed by an asymptote towards equilibrium, when plotted as a function of the square root of time.

Nevertheless, since the middle of the past century, papers studying mass diffusion in polymers related cases where it is not possible to describe the transport process by the direct application of Fick's law. These cases are called anomalous or non-Fickian diffusion. For example, Crank and Park [1] and Park [2] presented experimental evidence that the diffusion properties of a penetrant-polymer system change with time as diffusion proceeds. Nowadays, the non-Fickian behaviour of mass transport into polymers is the object of thousands papers.

Even though all the physical mechanisms of this behaviour are still unknown, the viscoelastic stress in the polymer is mentioned as one dominant factor $[3,4]$. This viscoelastic stress in polymers seems to be related to the concept of relaxation time, which measures the time it takes one portion of the polymer entanglement network to react to changes in another portion. In certain polymer-penetrant systems, this stress, which is a nonlinear memory effect, is as important to the transport process as the Fickian dynamics [4-6]. However, although often described, only few models exist attempting to quantify the phenomenon.

For the development of a quantitative model of non-Fickian mass transfer, we used a model system composed of polylactide (PLA) and cellulose nanocrystals (CNC) bearing different surface grafts. Indeed, PLA is one of the most popular biodegradable and biobased polymers. CNC are fully organic nanoparticles, receiving a huge academic and industrial research interest. Among their numerous advantages is their high surface reactivity, which eases surface grafting in the aim to tailor the interaction of CNC nanoparticles and the host polymer matrix. The fabrication of bio-based polymers including bio-based nanofillers has attracted particular interest in the domain of packaging, because it allows the making of claims such as $100 \%$ bio-based and biodegradable in applications [7]. The non-Fickian diffusion on PLA films was observed and analysed by several authors [8-10]. Davis et al. [10] analysed the non-Fickian diffusion using a two-stage diffusion-relaxation model based on the approach of Berens and Hopfenberg [11]. This model divides the total mass of penetrant uptake in the polymer into two parts: one for the Fickian process and the other for the relaxation

\footnotetext{
* Corresponding author.

E-mail address: giana.almeida@agroparistech.fr (G. Almeida).
} 
process. The relaxation is described by a series of simple first-order expressions. A similar approach was proposed for non-Fickian diffusion in wood [12]. Its main drawback is to assume the two mechanisms to be independent as relaxation is assumed to occur from the same initial time notwithstanding the position along the thickness. Such a model is therefore valid only when the characteristic time constants tied to diffusion and molecular relaxation are very contrasting. Moreover, to our knowledge, none of the proposed models found in the literature determine the diffusion behaviour by a coupled heat and mass transfer model.

This work uses a new formulation of coupled transfers with memory effect [13] to quantify the non-Fickian diffusion. This formulation is very robust and prone to be applied on films. The main advantages of this mathematical model is (i) to account for coupled heat and mass transfer and (ii) to quantify simultaneously the parameters related to the moisture transfer: the Fickian diffusion coefficient $D$ and the rate and magnitude of water uptake due to molecular relaxation (fraction of total water uptake $\alpha$ and relaxation time constant $\tau$ ).

\section{TransPoly: Mathematical model to quantify non-Fickian diffu- sion}

\subsection{Macroscopic formulation}

In the present work, the experimental data are analysed using a comprehensive formulation of coupled heat and mass transfer in a solid. Initially derived by volume averaging of heterogeneous media [1416], the formulation was adapted here to consider moisture diffusion in films. To that purpose, the comprehensive 3-state variable set of equations $[16,17]$ was reduced to a 2 -variable formulation. Such a set of equations account for the heat and mass coupling that usually exists as soon as evaporation or condensation takes place. This formulation, called TransPoly for Transfer through Polymers, includes the following assumptions:

- the medium consists of one single phase containing the polymer $\rho_{s}$ and bound water $\rho_{b}$,

- the solid density is assumed to be constant $\rho_{s}=$ constant,

- water molecules migrate as bound water diffusion,

- the water enthalpy $h_{b}$ equals the enthalpy of liquid water $h_{\ell}$ minus the differential heat of sorption, a decreasing function of moisture content,

The two independent equations needed to solve the spatio-temporal field come from balance equations:

Moisture conservation

$\frac{\partial \rho_{b}}{\partial t}+\nabla \cdot\left(\boldsymbol{J}_{b}\right)=0$

In Eq. (1), $\rho_{b}$ is the water density in the solid phase and $\boldsymbol{J}_{b}$ the diffusive flux of bound water.

Enthalpy conservation

$\frac{\partial}{\partial t}\left(\rho_{b} \bar{h}_{b}+\rho_{s} h_{s}\right)+\nabla \cdot\left(h_{b} \boldsymbol{J}_{b}\right)=\nabla \cdot(\lambda \nabla T)$

In Eq. (2), $h_{s}$ is the specific enthalpy of the polymer component of the solid phase, $\lambda$ the macroscopic conductivity of the solid phase and $h_{b}$ the specific enthalpy of bound water. As its value depends on bound water density, the averaged enthalpy $\bar{h}_{b}$ must be used in the accumulation term. Its value is defined as follows:

$\rho_{b} \bar{h}_{b}=\int_{0}^{\rho_{b}} h_{b}(\rho) d \rho$

In the case of a flat film submitted to symmetrical convective conditions, the geometrical configuration might be limited to one half thickness with the following boundary conditions:

At the exchange surface $(x=0)$

$\left.\boldsymbol{J}_{h}\right|_{x=0^{-}} \cdot \boldsymbol{n}=h_{h}\left(\left.T\right|_{x=0}-T_{\infty}\right)$
$\left.\boldsymbol{J}_{v}\right|_{x=0^{-}} \cdot \boldsymbol{n}=h_{m} c M_{v} \ln \left(\frac{1-x_{\infty}}{1-\left.x_{v}\right|_{x=0}}\right)$

where $\boldsymbol{J}_{h}$ and $\boldsymbol{J}_{v}$ are the water and heat fluxes in the boundary layer, $\boldsymbol{n}$ the external unit normal, $h_{h}$ and $h_{m}$ the heat and mass transfer coefficients, $x$ the molar fraction of water vapour. Indices $v$ and $\infty$ stands for the conditions outside of the boundary layer.

At the symmetry plane $(x=\ell / 2)$

$$
\begin{aligned}
& \left.\boldsymbol{J}_{h}\right|_{x=\ell / 2 s} \cdot \boldsymbol{n}=0 \\
& \left.\boldsymbol{J}_{b}\right|_{x=\ell / 2} \cdot \boldsymbol{n}=0
\end{aligned}
$$

\subsection{Bound water flux}

Assuming the fundamental statement that the flux is proportional to the gradient in chemical potential [18], the diffusive flux of bound water, $\boldsymbol{J}_{b}$, is expressed as:

$J_{b}=-\rho_{b} M_{b} \nabla \mu_{b}$

where $\rho_{b}$ is the density of bound water, $M_{b}$ the phase mobility and $\nabla \mu_{b}$ the gradient of chemical potential of bound water.

By definition, the chemical potential of bound water is equal to the chemical potential of water vapour in equilibrium with the moist polymer. The chemical potential of bound water can therefore be expressed as:

$$
\text { where } \quad \mu_{\ell}^{*}=\mu_{v}^{0}\left(T, P_{0}\right)+R T \ln \left(\frac{P_{v s}}{P_{0}}\right)
$$$$
\mu_{b}=\mu_{\ell}^{*}+R T \ln \left(\frac{P_{v}}{P_{v s}}\right)
$$

In these equations, $P_{v s}$ is the saturated vapour pressure, $P_{0}$ the reference pressure and $\mu_{v}^{0}$ the chemical potential of water vapour at temperature $T$ and pressure $P_{0}$. The ratio $P_{v} / P_{v s}$ involved in Eq. (8) is simply obtained via the sorption isotherm $p_{v}=p_{v s}(T) \times a_{w}$ (variables), where function $a_{w}$ is the water activity of the product, as defined by the sorption isotherm.

Generally, the sorption isotherm $a_{w}$ is assumed to be a function of temperature $T$ and moisture content $X=\rho_{b} / \rho_{s}$. In addition, we will neglect the moisture flux due to a gradient of temperature throughout the present work. This assumption is justified thanks to the simulation results of our 2-variable model that tells us that the temperature gradient remains negligible within the polymer film. In this case, the classical form of Fick's law can de derived from Eqs. (7) and (8):

$\begin{aligned} \boldsymbol{J}_{b} & =-\rho_{0} \boldsymbol{D}_{b} \nabla X \\ \text { with } \quad \boldsymbol{D}_{b} & =\frac{R T M_{b} X}{a_{w}} \frac{\partial a_{w}}{\partial X}\end{aligned}$

Remark. In the case of a simple linear relation between $a_{w}$ and $X$, Eq. (11) simplifies to $\boldsymbol{D}_{b}=R T M_{b}$.

\subsection{Molecular relaxation}

Molecular relaxation in polymers gives rise to non-Fickian behaviour: as macromolecular mobility needs time for the medium to reach equilibrium, the water activity $a_{w}$ in the polymer is not any more a simple function of temperature and moisture content: the product history must be considered to get the equilibrium water vapour pressure. This phenomenon can be approached using a relaxation function, defined by a sudden change of water activity, for example by a change of relative humidity $R H$ surrounding the product at a microscopic scale (Fig. 1). Let us assume that the water activity suddenly changes from $a_{w, i n i}$ to $a_{w, f i n}$, assuming the polymer to be at equilibrium at $t=0\left(X_{i n i}=X_{e q}\left(a_{w, i n i}\right)\right)$. In the case of a very small sample, the corresponding evolution of moisture content is therefore the signature of molecular relaxation only, which defines the intrinsic function $\varphi$ :

$X(t)-X_{i n i}=\Delta X_{e q} \times \varphi(t)$ 


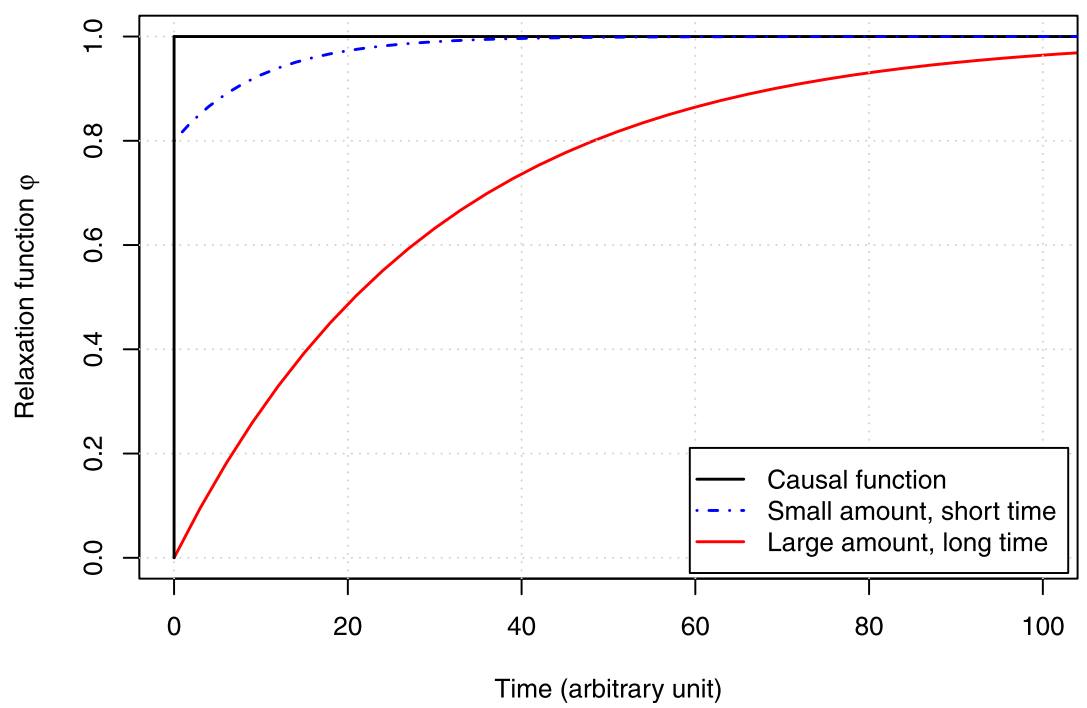

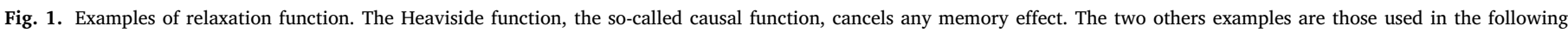
to analyse the effect of a relaxation function on transient diffusion.

where $\Delta X_{e q}$ is defined by the sorption isotherm values: $\Delta X_{e q}=X_{e q}$ $\left(a_{w, f i n}\right)-X_{e q}\left(a_{w, i n i}\right)$ and $\varphi$ a monotonic function such that: $\lim \varphi(t)_{t \rightarrow \infty}$ $=1$.

In this simple configuration, one must notice that the moisture content $X$ evolves in time whereas the water activity $a_{w}$ remains constant, equal to the imposed water activity $a_{w, \text { fin }}$. The chemical potential of water, the driving force for mass diffusion, remains therefore constant. This observation tells us that $X_{e q}$ must be used to formulate the diffusive flux, instead of the actual moisture content $X$.

Generally, the local value of water activity varies over time and Eq. (12) is not valid anymore. Instead, owing to the linearity of the problem, the rigorous formulation involves a convolution product:

$X(t)-X_{i n i}=\int_{0}^{t} \varphi(t-\tau) \frac{\partial X_{e q}}{\partial \tau} d \tau$

where

$\frac{\partial X_{e q}}{\partial \tau} d \tau=d X_{e q}$

which represents the variation of equilibrium moisture content during the infinitesimal time interval $d \tau$.

In order to derive the coupled set of macroscopic equations with memory effects, this new expression should be include in the conservation law for moisture. To that purpose, we have to remember that $X$ should be used for mass balance while $X_{e q}$, the variable tied to water activity $a_{w}$, should be used as driving force. Both quantities are function of space and time:

$\frac{\partial X(\boldsymbol{x}, t)}{\partial t}=\nabla \cdot\left(\boldsymbol{D}_{b} \nabla X_{e q}(\boldsymbol{x}, t)\right)$

Combining equations (13) and (15) allows a balance equation involving only $X_{e q}$ to be obtained:

$\frac{\partial}{\partial t}\left(\int_{0}^{t} \varphi(t-\tau) \frac{\partial X_{e q}(\boldsymbol{x}, \tau)}{\partial \tau} d \tau\right)=\nabla \cdot\left(\boldsymbol{D}_{b} \nabla X_{e q}(\boldsymbol{x}, t)\right)$

An integration by parts allows the classical formulation with memory effect to be obtained $[19,20]$ :

$\frac{\partial}{\partial t}\left(a X_{e q}(\boldsymbol{x}, t)+\int_{0}^{t} k(t-\tau) X_{e q}(\boldsymbol{x}, \tau) d \tau\right)=\nabla \cdot\left(\boldsymbol{D}_{b} \nabla X_{e q}(\boldsymbol{x}, t)\right)$ where

$a=\varphi(0) \quad$ and $\quad k=\frac{\partial \varphi}{\partial t}$

$a$ represents the instantaneous response of the solid moisture content when $X_{e q}$ varies. It stands for the part of the sorption behaviour considered as very fast regarding the process time. The memory function $k$ can be singular at $t=0$, but must be regular enough to have a smooth behaviour in the convolution product [21]. Obviously, the fading memory vanishes when function $\varphi$ is the causal function. In this case, the convolution product disappears.

One has however to keep in mind that Eq. (17) is not easy to handle for a multidimensional computational solution of coupled heat and mass transfer. The numerical implementation is much easier when the function $\varphi$ can be developed as a series of decreasing exponential functions. Such a series allows the convolution product to be turned into internal variables, whose evolutions obey simple ODEs.

$\varphi(t)=1-\sum_{i=1}^{N} \alpha_{i} \exp \left(-\frac{t}{\tau_{i}}\right)$

This expression is the sum of an instantaneous relaxation with proportion $\varphi(0)=1-\sum \alpha_{i}$ of the full change of equilibrium moisture content and a series of progressive relaxations of magnitude $\alpha_{i}$, with relaxation time $\tau_{i}$. In this case, Eq. (13) simplifies to:

$\begin{aligned} X(x, t) & =X_{e q}(x, t)-\sum_{i} \phi_{i}(x, t) \\ \text { where } \quad \phi_{i}(x, t) & =\int_{\tau=0}^{t} \alpha_{i} \exp \left(-\frac{t-\tau}{\tau_{i}}\right) d X_{e q}\end{aligned}$

The time evolution of each internal variable $\phi_{i}(x, t)$ can be derived from Eq. (20):

$\phi_{i}(\boldsymbol{x}, t+d t)=\exp \left(-d t / \tau_{i}\right) \phi_{i}(\boldsymbol{x}, t)+\alpha_{i} d X_{e q}(\boldsymbol{x}, t)$ 


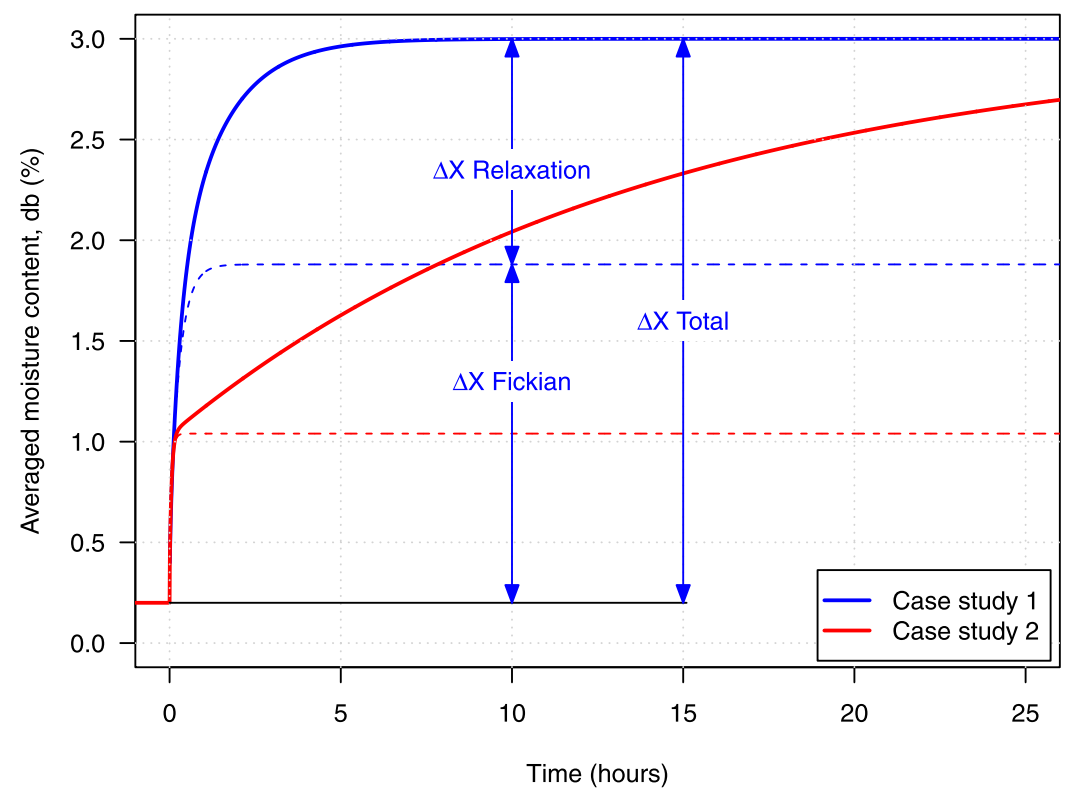

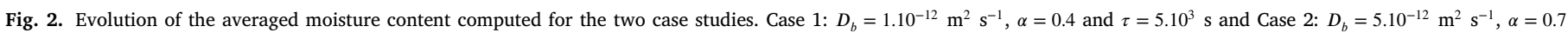
and $\tau=5.10^{4} \mathrm{~s}$.

The final set of coupled equation reads therefore as:

$$
\begin{aligned}
& \text { Moisture conservation } \\
& \frac{\partial X}{\partial t}=\nabla \cdot\left(\boldsymbol{D}_{b} \nabla X_{e q}\right)
\end{aligned}
$$

Energy conservation

$$
\frac{\partial}{\partial t}\left(\rho_{b} \bar{h}_{b}+\rho_{s} h_{s}\right)=\nabla \cdot\left(\lambda \nabla T+h_{b} \rho_{s} \boldsymbol{D}_{b} \nabla X_{e q}\right)
$$

Non-local equilibrium

$X_{e q}(\boldsymbol{x}, t)=X(\boldsymbol{x}, t)+\sum_{i} \phi_{i}(\boldsymbol{x}, t)$

Updating memory effects

$$
\begin{aligned}
\phi_{i}(\boldsymbol{x}, t+d t) & =\exp \left(-d t / \tau_{i}\right) \phi_{i}(\boldsymbol{x}, t)+\alpha_{i} d X_{e q}(\boldsymbol{x}, t) \\
\text { with } \quad d X_{e q}(\boldsymbol{x}, t) & =\frac{d X+\sum_{i} \phi_{i}(\boldsymbol{x}, t)\left(\exp \left(-d t / \tau_{i}\right)-1\right)}{\left(1-\sum_{i} \alpha_{i}\right)}
\end{aligned}
$$

\section{Remarks.}

- In Eqs. (24) to (26), the space variable $x$ was intentionally added to remind us that the proposed formulation considers the spatial position to account for the memory effect: each point has its own moisture history.

- Eq. (26) allows the evolution of $d X_{e q}$ to be computed from the evolution of $d X$, which in turn results from the mass balance equation. Note however that this expression requires $\varphi(0)$ to be strictly positive $\left(1-\sum_{i} \alpha_{i}>0\right)$. This is required to solve the system in terms of moisture content $X$.

This formulation is solved using an in-house software written in Fortran 95. The set of coupled and non-linear equations is integrated in time using a fully implicit scheme and a complete Newton-Raphson formulation. The total CPU time is of the order of the second, which is therefore a perfect physical engine for inverse analysis. The computational tool is embedded in a graphical interface using the graphical library Winteracter. This results in a Windows application, with fields for parameter input and output and curve plot for visual check. It can be used either to simulate desired configurations or to identified parameters values from a set of experimental data. In this case, the objective function is minimized using the Nelder-Mead algorithm [22]. The objective function is defined as the gap in average moisture content between theory and experiment, in the sense of mean-squared values, over a time interval that can be chosen by the user.

In the present work, the kernel function contains one single exponential term, as the inverse procedure becomes tricky when the number of degrees of freedom is too large. The relaxation function is therefore defined as:

$\varphi(t)=1-\alpha \exp \left(-\frac{t}{\tau}\right)$

For a proper analysis of the effect of the kernel function of the sorption behaviour, two simulation examples using different relaxation times $(\tau)$ and relaxation magnitudes $(\alpha)$ are presented hereafter. In both cases, a sudden change of $R H$, from $30 \%$ to $90 \%$ is imposed to a $100 \mu \mathrm{m}$ thick film. Two case studies are compared:

- Case study 1: $D_{b}=1.10^{-12} \mathrm{~m}^{2} \mathrm{~s}^{-1}, \alpha=0.4$ and $\tau=5.10^{3} \mathrm{~s}$

- Case study 2: $D_{b}=5.10^{-12} \mathrm{~m}^{2} \mathrm{~s}^{-1}, \alpha=0.7$ and $\tau=5.10^{4} \mathrm{~s}$

Fig. 2 exhibits the evolution of averaged moisture content (X) simulated with two sets of parameters. The contrast between the two characteristic times is not so large, the film attains its equilibrium quite rapidly (less than $2 \mathrm{~h}$ ). At first glance, the non-Fickian behaviour is not obvious, but was highlighted here by plotting only the contribution of Fickian diffusion without the relaxation effect (dashed line). In contrast, this non-Fickian behaviour appears very clearly for the case study 2, due to a characteristic time of molecular relaxation 10 times larger.

At very short sorption times, the condensation flux against the exchange faces of the films is quite intense. Due to the heat and mass coupling, this condensation flux gives rise to a temperature increase which slow down mass transfer via the effect of temperature on the saturated water vapour pressure. However, in the present configuration, this coupling is limited to the very short instants following the sudden change in RH. For the case study 1 , the temperature peak is at ca. $26^{\circ} \mathrm{C}$ (a temperature rise of ca. $1^{\circ} \mathrm{C}$ ). Then, the surface temperature decreases rapidly: at $0.5 \mathrm{~h}$, the temperature overshoot is already reduced to ca. $0.01^{\circ} \mathrm{C}$. This coupling would have been stronger for thinner films. 


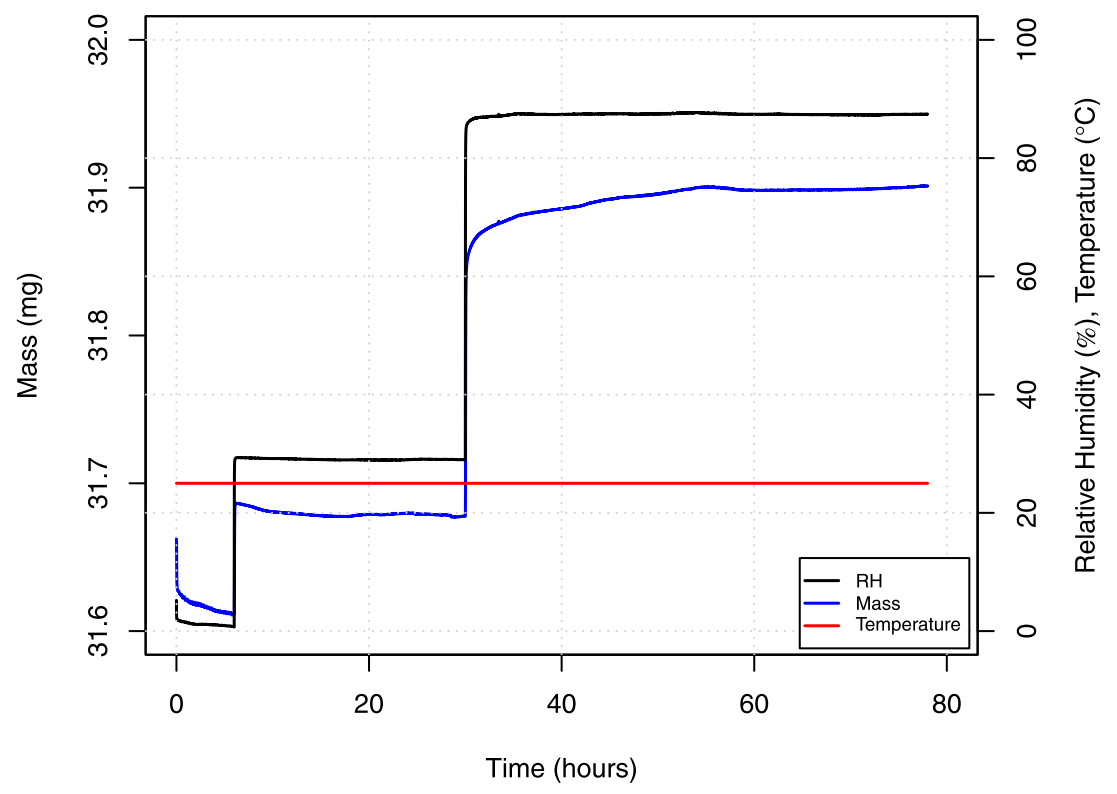

Fig. 3. Example of raw data, obtained by dynamic vapour sorption method, analysed by TransPoly to study the diffusion behaviour (sample CNC-g-BzAA6).

\section{Experimental data}

\subsection{Nanocomposite films}

Detailed information on the cellulose nanocrystals (CNC) and the surface esterification of the CNC used in the present work can be found in Espino-Pérez et al. [23].

Neat PLA and nanocomposite films were prepared using the casting method described in Espino-Pérez et al. [7]. In the present work, six films will be analysed: PLA, PLA/CNC $2 \mathrm{wt} \%$, PLA/CNC $6 \mathrm{wt} \%$, PLA/CNC 2 wt $\%$ grafted BzAA, PLA/CNC 6 wt $\%$ grafted BzAA and PLA/CNC 2 wt $\%$ grafted PhAA. Morphological and some physical properties of the films studied here can be found in Espino-Pérez et al. [7].

\subsection{Water sorption measurements}

Experimental data of water vapour sorption presented in [7] will be analysed in the present work. The water vapour sorption was performed by using dynamic vapour sorption with a DVS intrinsic apparatus (Surface Measurement Systems, London, UK). This equipment is composed by an ultra-sensitive micro-balance allowing the measurement of sample mass variations as low as $0.1 \mu \mathrm{g}$. The accuracy of the system is $0.5 \%$ for the relative humidity (RH) range 0 to $98 \%$ and $0.3{ }^{\circ} \mathrm{C}$ for a measuring temperature of $25{ }^{\circ} \mathrm{C}$. It must be highlighted that a support pan was specially designed to allow the entire film surface to be available for the vapour exchange. The samples (approximately 20 $\mathrm{mg}$ ) were first equilibrated at $0 \% \mathrm{RH}$ over $360 \mathrm{~min}$. The dry matter was determined at the end of this plateau. The RH was increased to $30 \%$ and maintained at this level for 1440 min. Finally, the RH was increased to $90 \%$ and maintained at this level for $2880 \mathrm{~min}$. Preliminary tests confirmed that the duration of each $\mathrm{RH}$ plateau was sufficient to attain the equilibrium condition (the rate of change of mass per unit time $(\mathrm{dm} / \mathrm{dt})$ was less than $0.0005 \% / \mathrm{min})$. The data were saved every $20 \mathrm{~s}$. The measurements were carried out in duplicate. One example of raw data is given in Fig. 3.

\section{Results and discussion}

\subsection{Parameter identification}

The model TransPoly was used to identify the film parameters by inverse analysis of the sorption tests (stepwise change of $\mathrm{RH}$ from
Table 1

Diffusion parameters calculated by TransPoly for the six films. Fickian diffusion coefficient $\left(D_{b}\right)$, Relaxation time $(\tau)$ and Relaxation proportion $(\alpha)$.

\begin{tabular}{lllll}
\hline Samples & $\begin{array}{l}\mathrm{CNC} \\
(\mathrm{wt} \%)\end{array}$ & $\begin{array}{l}D_{b} \\
\left(\times 10^{-12} \mathrm{~m}^{2} \mathrm{~s}^{-1}\right)\end{array}$ & $\begin{array}{l}\tau \\
(\mathrm{h})\end{array}$ & $\alpha$ \\
\hline PLA & 0 & 5.7 & 18.7 & 0.18 \\
PLA/CNC & 2 & 2.7 & 19.8 & 0.38 \\
PLA/CNC & 6 & 5.2 & 4.1 & 0.73 \\
PLA/CNC-g-BzAA & 2 & 5.4 & 8.0 & 0.07 \\
PLA/CNC-g-BzAA & 6 & 2.2 & 10.5 & 0.16 \\
PLA/CNC-g-PhAA & 2 & 4.8 & 11.1 & 0.15 \\
\hline
\end{tabular}

$30 \%$ to $90 \%$ ). As discussed in Section 2 , the identification procedure consists in tuning the initial set of parameters in order to minimize the difference between experiment and simulation. The difference is estimated as the mean squared distance over a given time interval and the objective function is minimized by the robust Nelder-Mead algorithm. The chamber conditions, as measured and recorded during the experiment, are supplied as boundary conditions to the model. This allows experimental data to be analysed even though the imposed conditions do not perfectly follow the desired values.

The predictions after identification are presented in Figs. 4 and 5 for the 6 films investigated here. In these figures, we can distinguish the Fickian and non-Fickian contributions during the water vapour uptake period. From these curves, we can note a first period with a very fast moisture uptake: the Fickian part takes ca. $30 \mathrm{~min}$ for all samples. This first period is followed by a second period which depicts a much slower water uptake due to molecular relaxation. The effect of the inclusion of CNC ( 2 and $6 \mathrm{wt} \%$ ) on the water vapour uptake greatly increases the amplitude of the water vapour uptake during this second period (Fig. 4). It is worth mentioning that this increase in nonFickian part correspond to an increase in final equilibrium moisture content. The increase of the non-Fickian part obvious for PLA/CNC films is not observed for grafted nanocomposites (PLA/CNC-g-BzAA 2 wt \%, PLA/CNC-g-BzAA 6 wt \% and PLA/CNC-g-PhAA 2 wt \%) (Fig. 5). Indeed, the kinetics of water vapour sorption of these films is similar to that of the PLA control.

The full set of parameters identified from the experimental data is summarized in Table 1 . The diffusion coefficient of water vapour in pure PLA $\left(D_{b}=5.7 \times 10^{-12} \mathrm{~m}^{2} \mathrm{~s}^{-1}\right)$ is of the same order of magnitude as other published works: $D_{b}=8.52 \times 10^{-12} \mathrm{~m}^{2} \mathrm{~s}^{-1}$ [10] and $D_{b}=$ 

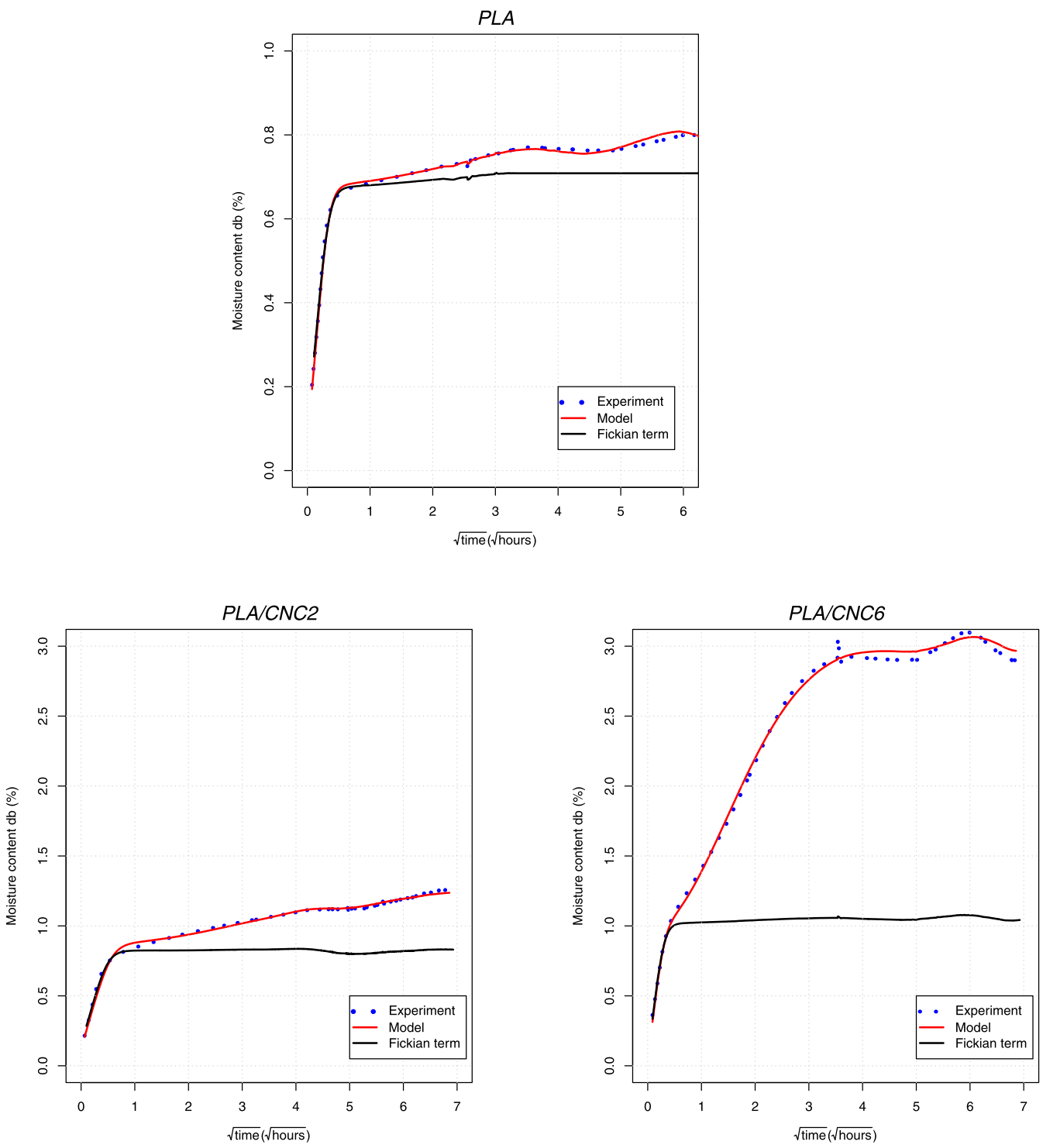

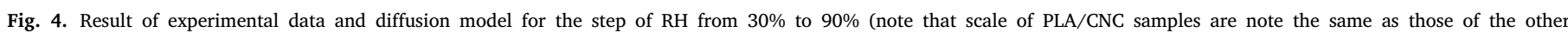
samples).

$3.63 \times 10^{-12} \mathrm{~m}^{2} \mathrm{~s}^{-1}$ [24]. It is interesting to note that the addition of pure $\mathrm{CNC}$ and grafted $\mathrm{CNC}$ did not affect significantly the diffusion coefficient. The shape factor of rod-like CNC is indeed not favourable for developing high tortuosity in the diffusive pathway.

Figs. 4 and 5 show that all samples feature non-Fickian mass transport. This is a common phenomenon observed in glassy polymers [11], but often overlooked in transport studies of polymers or nanocomposites. It is worth to mention that this non-Fikian behaviour can be observed because the experimental set-up uses thin films. Indeed, a small thickness decreases the characteristic time constant of diffusion, which varies as the squared thickness. This allows the diffusion time to be much smaller than the characteristic times of macromolecular relaxation, which are independent of thickness. We have then to keep in mind that a clear assessment of the anomalous diffusion is likely to be observed for thin films and long experimental times. This fact will be confirmed in the simulation section.

Results obtained by TransPoly (Table 1) clearly show that the presence of $\mathrm{CNC}$ affects the water sorption behaviour in the polymer relaxation controlled regime. The relaxation proportion $(\alpha)$ of the mass uptake of PLA/CNC 2 and $6 \mathrm{wt} \%$ are $38 \%$ and $73 \%$, respectively, against $18 \%$ only for the pure PLA film. TransPoly is also capable to determine the relaxation time (Table 1 ). The presence of CNC tends to decrease the relaxation time. The lowest relaxation time of $4 \mathrm{~h}$ of the $6 \mathrm{wt} \% \mathrm{CNC}$ nanocomposite might be explained by the presence of aggregates, as shown by Espino-Pérez et al. [7].

Cluster formation of water inside polymers is a largely described phenomenon. Davis et al. [9] showed that cluster occurs in PLA starting form a HR of $65 \%$. Concerning the role of hydrophilic nanofillers on water vapour transfer through films, Drozdov et al. [25] suggested that water clustering at the surface of Montmorillonite clays can cause a deceleration of diffusion but increase the sorption phenomena. Follain et al. [26] studied the water penetration through PCL (Poly ( $\epsilon$-caprolactone))/CNC nanocomposites. They suggested that PCL and nanocomposites became plasticized by the water and that the water travelled along the interfaces. Choudalakis and Gotsis [27] proposed that the presence of aggregates of inorganic nanofillers at high filling loads would increase the available free volume for penetrant sorption in polymer-depleted zones. According to Espino-Pérez et al. [7], water vapour is present as clusters in the nanocomposites structure and there is a preferential sorption of water in the PLA/CNC interface and in the CNC. Water vapour preferentially swells the CNC due to the higher chemical affinity, which allows increased water uptake without much change to the overall Fickian diffusion coefficient. As the swelling of the CNC becomes significant, the water finds a preferential path of diffusion 

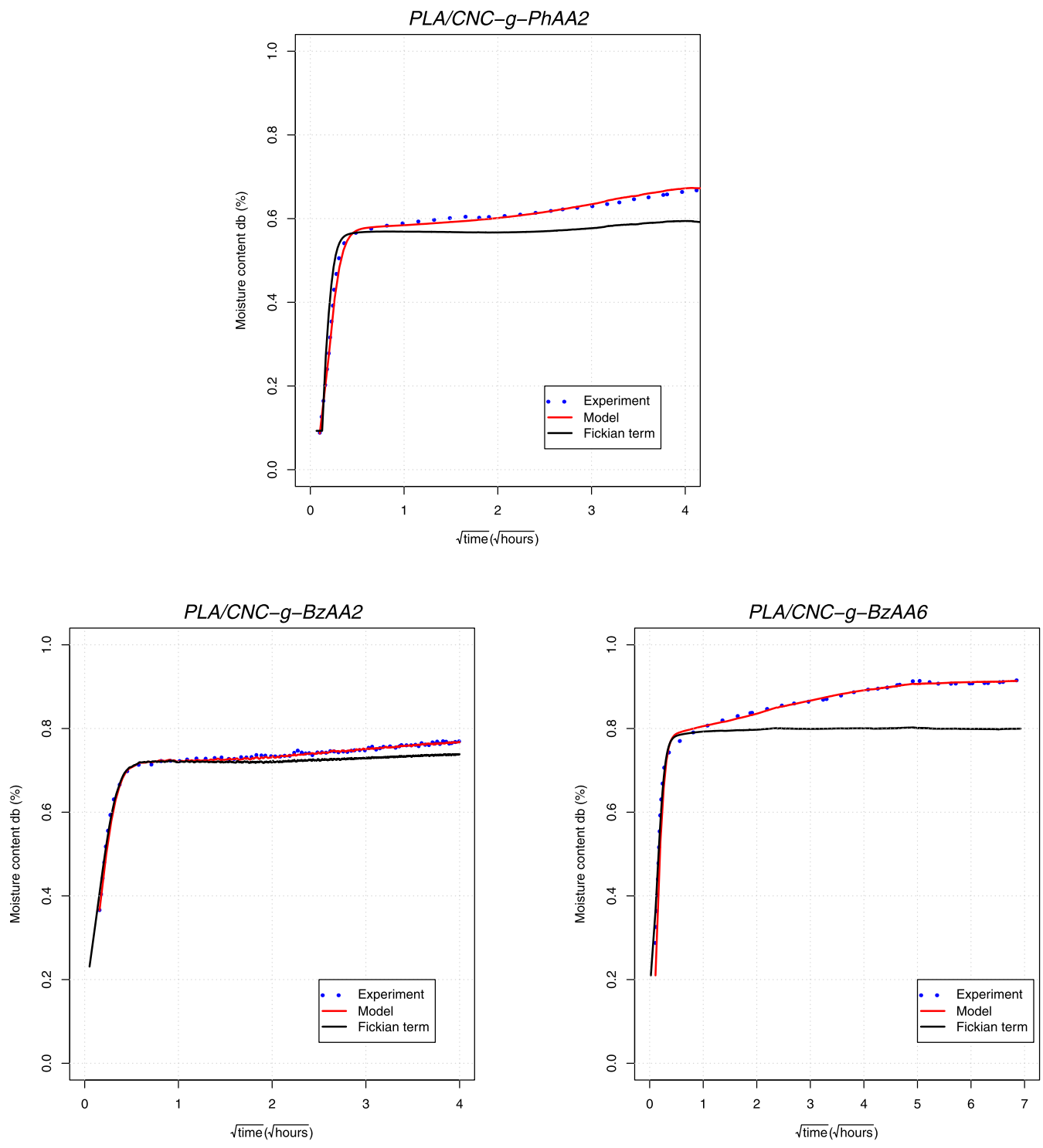

Fig. 5. Result of experimental data and diffusion model for the step of $\mathrm{RH}$ from $30 \%$ to $90 \%$ (cont.).

through the swollen CNC. Surface grafting decreases this phenomenon. The presence of aggregates in the PLA/CNC 6 wt\% further increases the sorption phenomenon and mass transport due to the creation of polymer-depleted voids. These aggregates can also create percolation paths, facilitating the mass transfer through the film (Fig. 6). EspinoPérez et al. [28] studied the water vapour isotherms at $25{ }^{\circ} \mathrm{C}$ of CNC and grafted CNC powders. They observed that the equilibrium moisture content $\left(X_{e q}\right.$ ) of CNC powders was of $98.5 \%$ (at $82 \% \mathrm{HR}$ ). $X_{e q}$ values of CNC grafted powders were only $10.8 \%$ for CNC-g-BzAA (at $79 \% \mathrm{HR}$ ) and $9.8 \%$ for CNC-g-PhAA (at 93\% HR). Table 1 shows that the lower hygroscopicity of CNC grafted powders affects the diffusion behaviour of films composed by these nanocomposites, since the relaxation proportion $(\alpha)$ values of these samples were at the same order of magnitude of PLA control (18\%) or even lower. For example, in PLA/CNC-g-BzAA $2 \mathrm{wt} \%$ film, only $7 \%$ of the water vapour mass uptake is controlled by the non-Fikian behaviour.

As shown in Fig. 6, these aggregates can facilitate the water vapour percolation through the sample, lowering by at least a half the relaxation time through the sample. The presence of the hydrophilic CNC structures increased the water uptake of the nanocomposites in the relaxation-controlled regime. The high affinity to water vapour of $\mathrm{CNC}$ is corroborated by results of Espino-Pérez et al. [28]. As a conclusion, the design of less polar surfaces of CNC allowed for importantly decreasing the non-Fickian mass transfer dynamics.

\subsection{Prediction of transfer dynamics}

Once the transfer parameters of a given film have been determined by inverse analysis from experimental data, the sorption behaviour can be predicted thanks to TransPoly for different configurations. In this section, we used the parameters obtained for two films (PLA/CNC6 and PLA/CNC-g-BzAA6) to simulate the same sorption test (stepwise change of $\mathrm{RH}$ from $30 \%$ to $90 \%)$, but for different thicknesses $(25 \mu \mathrm{m}, 50 \mu \mathrm{m}$, $100 \mu \mathrm{m}, 200 \mu \mathrm{m}, 400 \mu \mathrm{m}$ ). These values should be considered as halfthicknesses with symmetrical conditions (for example the configuration of the sorption tests performed in this study) or as the full film thickness in the case of asymmetrical conditions (packaging for example).

Fig. 7 depicts the sorption kinetics simulated for PLA/CNC6. As the time axis (x-axis) is the square root of time, the short-time behaviour, dominated by Fickian diffusion, appears as a straight line. The slope of this line varies as the thickness. On the contrary, the time constant of the non-Fickian part is independent on the thickness. The behaviour at long times, dominated by molecular relaxation, depicts the same trend, 

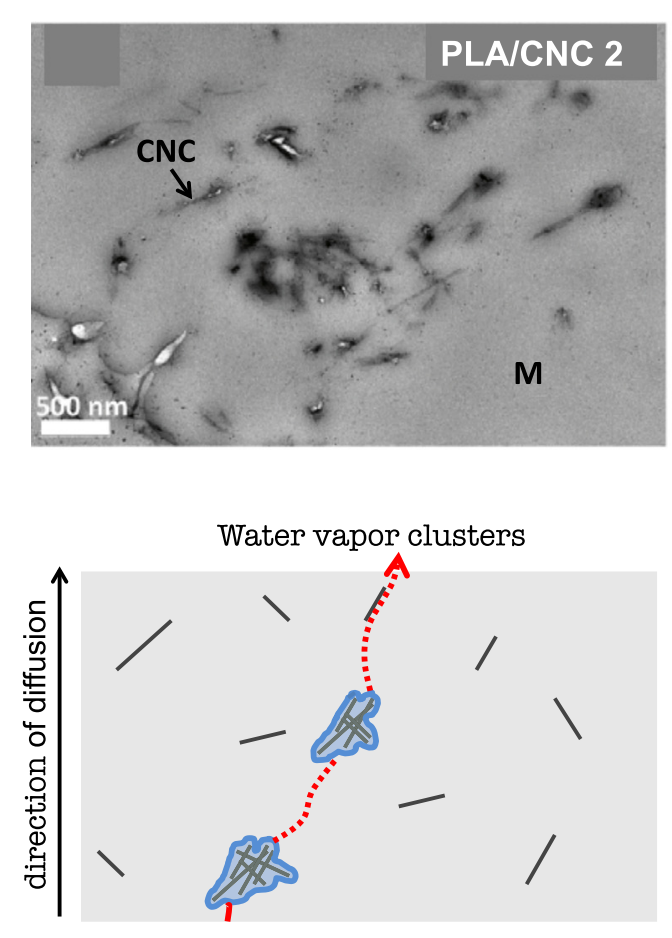

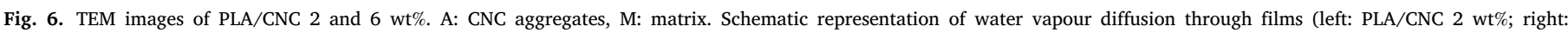
PLA/CNC $6 \mathrm{wt} \%$ ).

Source: TEM images were modified from Espino-Pérez et al. [7].

whatever the thickness values. Consequently, for thin films, both effects are easy to distinguish while, for the largest thickness value, the slopes are identical. For the $400 \mu \mathrm{m}$ thick film, the whole curve resembles a pure Fickian behaviour, that would have been misleading.

The moisture content profiles computed for 2 contrasted thicknesses: $50 \mu \mathrm{m}$ and $400 \mu \mathrm{m}$ give further insights on the intricate effects of diffusion and molecular relaxation (Fig. 8). At short times $(0.01 \mathrm{~h}$ for the $50 \mu \mathrm{m}$ thick film and up to $0.2 \mathrm{~h}$ for the $400 \mu \mathrm{m}$ thick film), classical diffusion profiles can be recognized. Consistently, their amplitude is controlled by the value of $\alpha$ and concerns, for this film, ca. 1/4 of the total water uptake. Then, the process slows down due to the relaxation effect. For the thinner film (left-hand side of Fig. 8), flat moisture content profiles are observed after the very fast transient diffusion period. For this very thin film, both phenomena, diffusion and molecular relaxation, are almost fully separated: pure diffusion takes place first and then, once molecular relaxation is expressed, with moisture content profiles remaining flat. The starting time for molecular relaxation is indeed almost independent of space and the following profiles tends towards the final equilibrium uniformly in space. In such case, a model considering the variation of moisture content as a sum of two contributions would have been justified.

For the thick film (right-hand side of Fig. 8), step profiles persist over more than $10 \mathrm{~h}$, with a MC value larger at the exchange face $(x=0)$. The profiles seem to be simply shifted in time towards larger MC values. Indeed, the difference of RH history between the surface and the core of the film due to diffusion is large enough in comparison to molecular relaxation to maintain a difference in moisture content. During a quit long time interval, diffusion and molecular relaxation coexist. This physical feature is embedded in the convolution product of Eq. (17). This case is a typical example of characteristic time constants for which both phenomena (diffusion and relaxation) cannot be decoupled. At very long times, the memory was completely erased to give rise to a flat profile at the equilibrium moisture content $\left(X_{e q}\right)$.
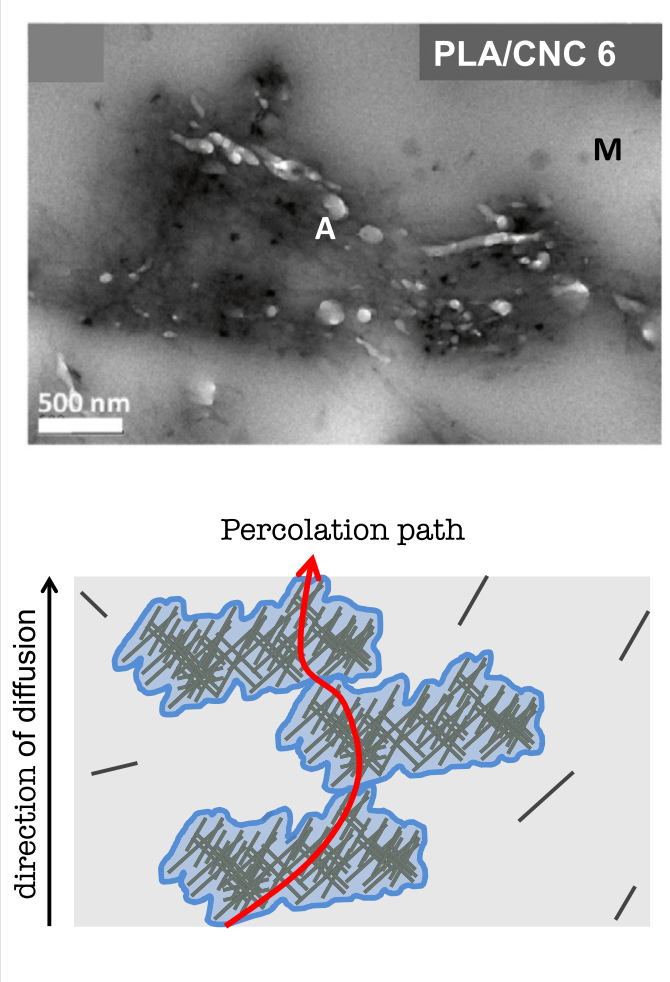

The similar simulation results for different thicknesses of PLA/CNCg-BzAA6 film are depicted in Figs. 9 and 10. The general trends are similar to the previous film, but with differences due to the different values of parameters (see Table 1 ):

- the smaller value of diffusivity extents the duration of the diffusive period (for example $1 \mathrm{~h}$ for the $100 \mu \mathrm{m}$-thick film against $0.4 \mathrm{~h}$ for the same thickness of PAL/CNC6 film),

- the reduced amplitude of the non-Fickian contribution to the total water uptake (16\% instead of $73 \%)$ is obvious on kinetics and profiles,

- the same observations can be drawn, in spite of the differences in order of magnitude, regarding the profiles shape: diffusion and molecular relaxation can be decoupled for the thin film but should be considered simultaneously for the thick film.

The last comment is devoted to the coupling between heat and mass transfer. As mentioned in the modelling section, we proposed a 2variable model, likely to consider the coupling between heat and mass transfer. Similarly, the boundary conditions (eq. (5)) used the concept of film theory [29]. The proposed formulation is therefore ready to address the coupling between heat and mass transfer, including those occurring at temperature levels close to the boiling point of water. The main interest of this formulation is to take into account the effect of phase change of water (condensation or evaporation), given the huge difference in enthalpy between liquid water and water vapour. The primary effect of this coupling occurs at the exchange surface of the product: the water migrates as water vapour inside the boundary layer and as bound water inside the product. The phase change therefore occurs at the boundary of the product and always slows down the mass transfer [30]. In the case of condensation, the product surface heats up, which increases the vapour surface pressure due to the effect of temperature on the saturated vapour pressure. This change reduces the driving force through the boundary layer. In the case of evaporation, 


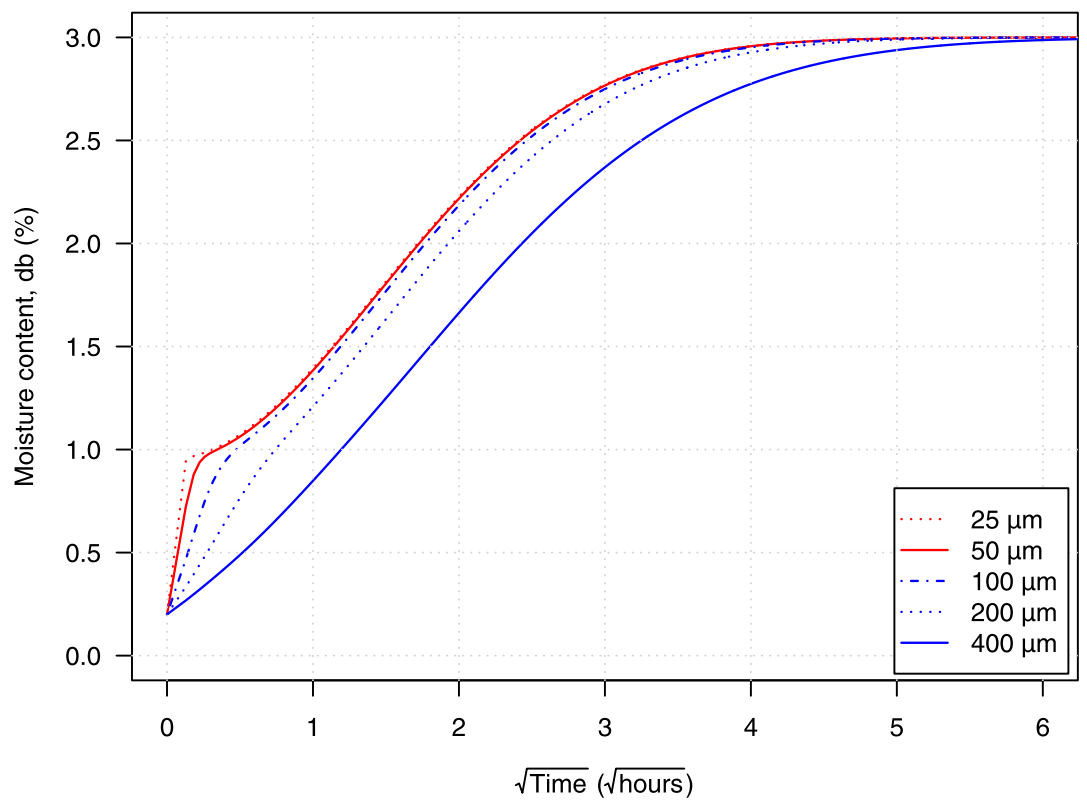

Fig. 7. Evolution of the averaged moisture content computed for different thicknesses using the parameters identified for the PLA/CNC6 film.
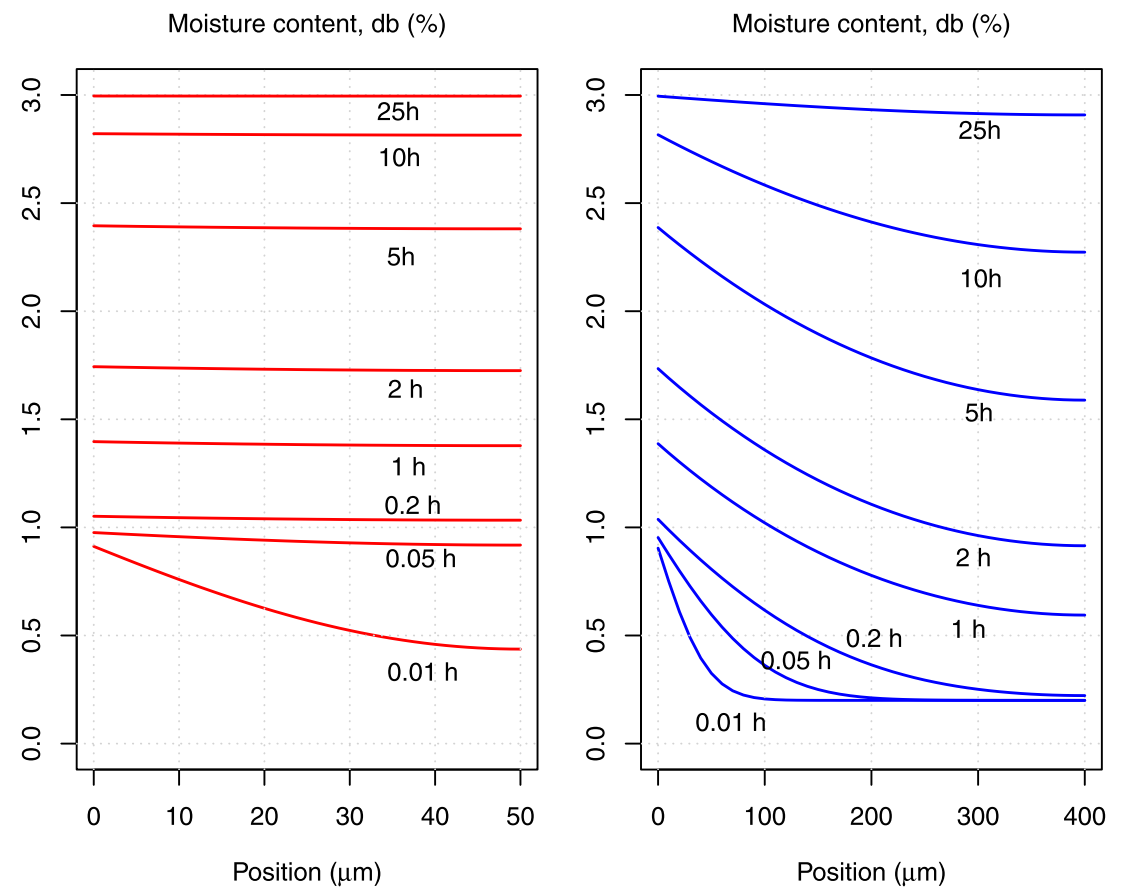

Fig. 8. Simulated moisture content profiles (PLA/CNC6 film) for the two contrasted thicknesses: $50 \mu \mathrm{m}$ (left) and $400 \mu \mathrm{m}$ (right).

the surface cooling reduces the vapour pressure at the surface and, again, reduces the driving force through the boundary layer.

For the configurations considered in this work, the coupling remains weak. The highest coupling value is obtained for the smallest thickness $(50 \mu \mathrm{m})$. For this thickness, the Drying Intensity Number introduced in [17] is of the order of 100, well above unity, indicating a weak coupling between heat and mass transfer.

The computer simulation confirms this weak coupling: the maximum surface temperature reaches $25.4{ }^{\circ} \mathrm{C}$ at $5 \mathrm{~min}$ (a temperature increase of $0.4{ }^{\circ} \mathrm{C}$. By simulating the same configuration without coupling (the enthalpy of the water vapour was set equal to that of liquid water), a very weak effect on the diffusive part is obtained (a variation in the diffusion coefficient of about $1 \%$ ). Under such conditions, the effect of the differential heat of sorption is even more negligible.
Not surprisingly, the very slow phase due to molecular relaxation is absolutely unaffected by the coupling.

It should be noted that, even if the coupling is weak, the 2-variable model allowed us to quantify its importance. Moreover, different configurations, such as high temperature configurations, could lead to stronger coupling due to thermo-activation of diffusion.

\section{Conclusion}

The present work proposes a new model to study mass transfer through polymers (TransPoly). This spatio-temporal mathematical model, based on coupled heat and mass transfer, involves a memory function that allows the main parameters related to the diffusion process to be quantified: the Fickian diffusion coefficient, the rate of mass 


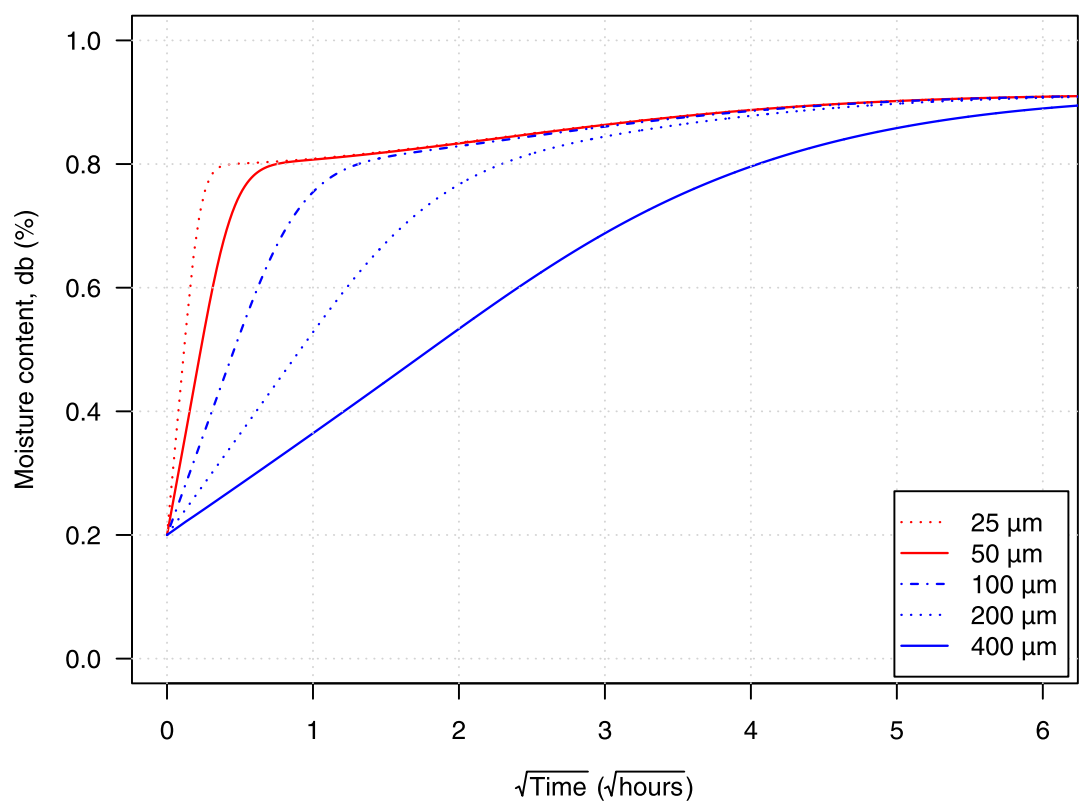

Fig. 9. Evolution of the averaged moisture content computed for different thicknesses using the parameters identified for the PLA/CNC-g-BzAA6 film.
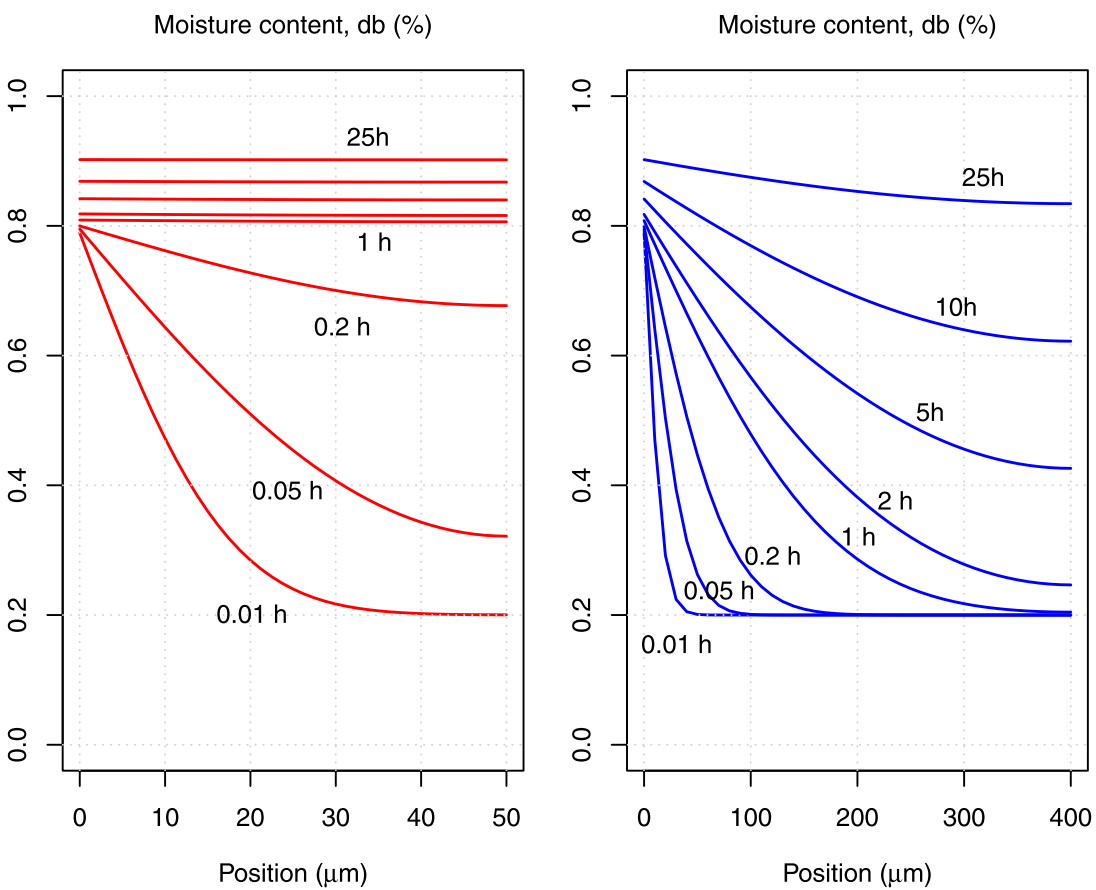

Fig. 10. Simulated moisture content profiles (PLA/CNC-g-BzAA6) for the two contrasted thicknesses: $50 \mu \mathrm{m}$ (left) and $400 \mu \mathrm{m}$ (right).

uptake due to molecular relaxation and the time constant of relaxation. This model was applied to PLA/CNC films. All films studied presented non-Fickian diffusion, but at different proportions depending on the composition and proportion of nanofillers. TransPoly was able to show that the non-Fickian behaviour can represent up to $73 \%$ of the total water uptake: ignoring this behaviour in the use of these polymers can be seriously misleading.

The main conclusions of the present work are:

- Experiments on thin films over long durations are needed to exhibit clearly both the Fickian diffusion and the molecular relaxation;
- Once the parameters of the comprehensive model have been identified on experimental data, the model is able to predict the film behaviour for different conditions. For example, simulations proved that the behaviour of thick films is explained by the coexistence of both phenomena over a large period of time, even though their global kinetics resemble that of a pure Fickian material;

- Nanocomposites can be analysed with TransPoly model. The nature of the nanoparticle and of its surface can have substantial contribution to the behaviour of the relaxation controlled mass transport. 
Table 2

Latin symbols.

\begin{tabular}{lll}
\hline Symbol & Name & Unit \\
\hline$c$ & Molar concentration & $\mathrm{mole} \mathrm{m}^{-3}$ \\
$D$ & Diffusion coefficient & $\mathrm{m}^{2} \mathrm{~s}^{-1}$ \\
$h$ & Specific enthalpy & $\mathrm{J} \mathrm{kg}^{-1}$ \\
$h_{h}$ & Heat transfer coefficient & $\mathrm{W} \mathrm{m} \mathrm{K}^{-1}$ \\
$h_{m}$ & Mass transfer coefficient & $\mathrm{m} \mathrm{s}^{-1}$ \\
$\boldsymbol{J}_{b}$ & Bound water flux & $\mathrm{kg} \mathrm{m}^{-2} \mathrm{~s}^{-1}$ \\
$\boldsymbol{J}_{q}$ & Heat flux & $\mathrm{W} \mathrm{m}^{-2}$ \\
$M$ & Molar mass & $\mathrm{kg} \mathrm{mole}^{-1}$ \\
$M_{b}$ & Mobility of bound water & $\mathrm{mole} \mathrm{m}^{2} \mathrm{~s}^{-1} \mathrm{~J}^{-1}$ \\
$n$ & Normal unit vector & - \\
$R H$ & Relative humidity & - \\
$t$ & Time & $\mathrm{s}$ \\
$T$ & Temperature & $\mathrm{K} \mathrm{or}{ }^{\circ} \mathrm{C}$ \\
$x$ & Molar fraction & - \\
$\boldsymbol{x}$ & Position & $\mathrm{m}$ \\
$X$ & Solid moisture content (dry basis) & - \\
\hline Bold font & Vector or tensor & \\
\hline & & \\
\hline
\end{tabular}

Table 3

Greek and math symbols.

\begin{tabular}{lll}
\hline Symbol & Name & Unit \\
\hline$\alpha$ & Pre-exponential factor & - \\
$\lambda$ & Thermal conductivity & $\mathrm{W} \mathrm{m}^{-1} \mathrm{~K}^{-1}$ \\
$\varphi$ & Memory function & - \\
$\phi$ & Internal variable & - \\
$\mu$ & Chemical potential & $\mathrm{J} \mathrm{mole}$ \\
$\rho$ & Density & $\mathrm{kg} \mathrm{m}^{-3}$ \\
$\tau$ & Time constant & $\mathrm{s}$ \\
$\partial$ & Partial derivative & - \\
$\nabla$ & Gradient & - \\
$\nabla$ & Divergence & - \\
\hline
\end{tabular}

Table 4

Subscripts and superscripts.

\begin{tabular}{ll}
\hline Subscripts & Meaning \\
\hline$a$ & Air \\
$b$ & Bound water \\
$e q$ & Equilibrium \\
ini & Initial value \\
fin & Final value \\
$v$ & Water vapour \\
$v s$ & Saturated water vapour \\
$\infty$ & Outside the boundary layer \\
\hline
\end{tabular}

\section{Declaration of competing interest}

The authors declare that they have no known competing financial interests or personal relationships that could have appeared to influence the work reported in this paper.

\section{CRediT authorship contribution statement}

Giana Almeida: Methodology, Investigation, Conceptualization, Writing - original draft, Writing - review \& editing. Sandra Domenek: Methodology, Conceptualization, Funding acquisition, Writing - review \& editing. Patrick Perré: Formal analysis, Software, Conceptualization, Writing - review \& editing.

\section{Acknowledgments}

Financial supports from Grand Reims, the Marne department and the Grand Est region are gratefully acknowledged.

\section{Appendix. Notations}

The notations are summarized in Tables 2 to 4 .

\section{References}

[1] J. Crank, G.S. Park, Diffusion in high polymers: some anomalies and their significance, Trans. Faraday Soc. 47 (1951) 1072-1084.

[2] G.S. Park, An experimental study of the influence of various factors on the time dependent nature of diffusion in polymers, J. Polym. Sci. 11 (2) (1953) 97-115.

[3] J. Crank, A theoretical investigation of the influence of molecular relaxation and internal stress on diffusion in polymers, J. Polym. Sci. 11 (2) (1953) 151-168.

[4] D.A. Edwards, Nonfickian diffusion in thin polymer films, J. Polym. Sci. B 34 (5) (1996) 981-997.

[5] W. Vieth, K. Sladek, A model for diffusion in a glassy polymer, J. Colloid Sci. 20 (9) (1965) 1014-1033.

[6] H.L. Frisch, Sorption and transport in glassy polymers-a review, Polym. Eng. Sci. 20 (1) (1980) 2-13.

[7] E. Espino-Pérez, J. Bras, G. Almeida, C. Plessis, N. Belgacem, P. Perré, S. Domenek, Designed cellulose nanocrystal surface properties for improving barrier properties in polylactide nanocomposites, Carbohydr. Polymers 183 (2018) 267-277.

[8] S. Marais, M. Métayer, Q.T. Nguyen, M. Labbé, D. Langevin, New methods for the determination of the parameters of a concentration-dependent diffusion law for molecular penetrants from transient permeation or sorption data, Macromol. Theory Simul. 9 (4) (2000) 207-214.

[9] E.M. Davis, M. Minelli, M.G. Baschetti, G.C. Sarti, Y.A. Elabd, Nonequilibrium sorption of water in polylactide, Macromolecules 45 (18) (2012) 7486-7494.

[10] E.M. Davis, M. Minelli, M.G. Baschetti, Y.A. Elabd, Non-fickian diffusion of water in polylactide, Ind. Eng. Chem. Res. 52 (26) (2013) 8664-8673.

[11] A. Berens, H. Hopfenberg, Diffusion and relaxation in glassy polymer powders: 2. separation of diffusion and relaxation parameters, Polymer 19 (5) (1978) 489-496.

[12] W. Olek, R. Romain, J. Weres, P. Perré, Non-fickian moisture diffusion in thermally modified beech wood analyzed by the inverse method, Int. J. Therm. Sci. 109 (2016) 291-298.

[13] P. Perré, Coupled heat and mass transfer in biosourced porous media without local equilibrium: a macroscopic formulation tailored to computational simulation, Int. J. Heat Mass Transfer 140 (717-730).

[14] W. Gray, A derivation of the equations for multiphase transport, Chem. Eng. Sci. 30 (1975) 229-233.

[15] S. Whitaker, Coupled transport in multiphase systems: a theory of drying, in: Y.I.C.J.P. Hartnett, T.F. Irvine, G.A. Greene (Eds.), Advances in Heat Transfer, Vol. 31, Elsevier, 1998, pp. 1-104.

[16] P. Perré, R. Remond, I.W. Turner, Comprehensive drying models based on volume averaging: Background, application and perspective, in: E. Tsotsas, A.S. Mujumdar (Eds.), Modern Drying Technology, Vol. 1, in: Computational Tools at Different Scales, Wiley-VCH, 2007, pp. 1-55, Ch. 1.

[17] P. Perré, The proper use of mass diffusion equations in drying modeling: Introducing the drying intensity number, Drying Technol. 33 (15-16) (2015) 1949-1962.

[18] J.G. Wijmans, R.W. Baker, The solution-diffusion model: a review, J. Membr. Sci. 107 (1-2) (1995) 1-21.

[19] R.E. Showalter, Diffusion models with microstructure, Transp. Porous Media 6 (1991) 567-580

[20] R.E. Showalter, Distributed microstructured models of porous media, Int. Ser. Numer. Math. 114 (1993) 155-163.

[21] M. Peszynska, Analysis of an integro-differential equation arising from modelling of flows with fading memory through fissured media, J. Partial Differ. Equ. 8 (1995) 159-173.

[22] J.A. Nelder, R. Mead, A simplex method for function minimization, Comput. J. 7 (4) (1965) 308-313.

[23] E. Espino-Pérez, S. Domenek, N. Belgacem, C. Sillard, J. Bras, Green process for chemical functionalization of nanocellulose with carboxylic acids, Biomacromolecules 15 (12) (2014) 4551-4560, http://dx.doi.org/10.1021/ bm5013458.

[24] M. Martínez-Sanz, A. Lopez-Rubio, J.M. Lagaron, Optimization of the dispersion of unmodified bacterial cellulose nanowhiskers into polylactide via melt compounding to significantly enhance barrier and mechanical properties, Biomacromolecules 13 (11) (2012) 3887-3899.

[25] A.D. Drozdov, J. de C. Christiansen, R.K. Gupta, A.P. Shah, Model for anomalous moisture diffusion through a polymer-clay nanocomposite, J. Polym. Sci. B 41 (5) (2003) 476-492.

[26] N. Follain, S. Belbekhouche, J. Bras, G. Siqueira, S. Marais, A. Dufresne, Water transport properties of bio-nanocomposites reinforced by luffa cylindrica cellulose nanocrystals, J. Membr. Sci. 427 (2013) 218-229.

[27] G. Choudalakis, A. Gotsis, Free volume and mass transport in polymer nanocomposites, Curr. Opin. Colloid Interface Sci. 17 (3) (2012) 132-140.

[28] E. Espino-Pérez, J. Bras, G. Almeida, P. Relkin, N. Belgacem, C. Plessis, S. Domenek, Cellulose nanocrystal surface functionalization for the controlled sorption of water and organic vapours, Cellulose 23 (5) (2016) 2955-2970.

[29] R.B. Bird, W.E. Stewart, E.N. Lightfoot, Transport Phenomena, second ed., John Wiley \& Sons, New York, 2002.

[30] P. Perré, A. Challansonnex, J. Colin, On the importance of heat and mass transfer coupling for the characterization of hygroscopic insulation materials, Int. J. Heat Mass Transfer 133 (2019) 968-975. 